\title{
EXPERIMENTAL INVESTIGATION OF THE RELATIONSHIP BETWEEN NOISE LEVEL AND THERMAL POWER INSIDE THE BOILER PLANT - STUDY CASE
}

\author{
CATALIN BAILESCU - Research center CAMBI, Technical University of Civil Engineering, \\ e-mail: catalin.bailescu@gmail.com \\ VLAD IORDACHE - Research center CAMBI, Technical University of Civil Engineering, \\ e-mail: viordach@yahoo.com \\ FLORIN IORDACHE - Research center CAMBI, Technical University of Civil Engineering, \\ e-mail: fliord@yahoo.com
}

ADRIAN MARIN - Research center CAMBI, Technical University of Civil Engineering, e-mail: adrian.marin@gmail.com

\begin{abstract}
The acoustic comfort of a building or house is typically given little or no attention during project planning and design. This study is aimed at quantifying noise pollution from a building technical room. To attain the research specified result, simultaneous measurements were recorded for the gas flow and noise level in the boiler room. The noise levels were recorded for different operation statuses of the boilers (different thermal loads). It was observed that noise level depends on the thermal load: the increase of thermal load is directly proportional to the noise level inside the plant room). Further, the measured values of the noise level were compared with literature predicted values and the maximum limit values from the Romanian norm. These research findings are useful for mechanical design engineers and architects in order to assure the noise protection and fulfill the residents' expectations.
\end{abstract}

Keywords: acoustic comfort, noise level, measurements, boiler plant

\section{Introduction}

Beside the already recognized indoor comfort categories (thermal, illumination, pollution), the acoustic comfort becomes an increasingly important aspect nowadays both nationally and internationally.

As a result, national standards have been adopted in several countries by setting maximum noise levels for different environments. These standards vary from one country to another and in the United States have been imposed in the form of recommendations [3], guidelines [4] or statutory requirements [5]. In the European Community the limits of noise level are imposed by mandates regulations of noise exposure [6] and noise evaluation standard [7].

In Romania, the acoustics norm in constructions and urban areas [8] prescribes admissible limits established considering the appropriate climate specific to the use and the indoor destination of the space.

Because road traffic noise is considered the main source of loss of environmental and life in a metropolis [10] much of previous studies on acoustic comfort has been focused on road, rail and air traffic [11-13]. However achieving acoustical comfort in buildings it is not just about reducing this type of noise, because in several previous studies [14-15] has been reported that in residential building an important source of acoustic discomfort is noise from boiler plant. The noise prediction from technical room is an important consideration in the design stage, operation and construction of all buildings.

In [9] two methods of predicting the noise level in the technical spaces are proposed. The first model [1] established by Cyssau in 1997 shows a formula established following a study of a 145 database of thermal power plants under $16 \mathrm{MW}$ designed to present the relationship between the noise level of thermal power plants and their thermal power:

$$
\mathrm{L}_{\mathrm{p}}=10 \cdot \log _{10}(\mathrm{P})+55
$$


This prediction model is characterized by a 10 [dBA] error. Another method [2] predicts the noise level inside thermal plants as a function of both the thermal power and the volume of the thermal plant:

$$
\mathrm{L}_{\mathrm{p}}=16 \log \mathrm{Q}-10 \log \mathrm{V}+54[\mathrm{dBA}]
$$

which is characterized by a $5[\mathrm{dBA}]$ error.

These noise prediction models are characterized by large errors and rises questions regarding their suited for today's thermal equipment. In this analysis we will analyse if these models are adapted to today's boiler plant equipment or it is necessary to create a new prediction model of noise level for design stage.

The study follows an experimental approach. Simultaneous measurements of thermal power and the noise level were recorded in order to understand the relationship between the noise level and the thermal power generated inside the thermal plant. The noise level ware recorded for different operation status of the boilers (different thermal loads) and was compared to the value required by [8] and predictions method [1],[2].

The paper presents the experimental results of noise level inside one a technical room, the recordings database, results and discussions.

\section{Experiments}

The measurements were carried out by a team of three people: one person registers the gas index, another one operates the boiler automation, and the third person carries out the noise measurements.

The analysed thermal plant is a stand-alone building located next to the appartment blocks (Fig.1a) in Ploiesti town, Romania. It has a 3.3MW thermal power capacity and serves 6 blocks of dwellings of ten floors height.

The thermal plant room is rectangular shaped (dimensions: $17.72 \mathrm{~m}$ long, $8.90 \mathrm{~m}$ wide and $4.67 \mathrm{~m}$ height, volume $736.49 \mathrm{~m}^{3}$.) (Fig. 1c). The walls of the boiler plant are made of brick, hardwood, and the finished concrete floor. The two windows have a metal frame with a single sheet of glass and at tiled floor. Surface of walls, ceilings and floors are of reflective materials, so the room absorption coefficient is very low.

The thermal plant has two 1400KW Chappee Arizona HR2 boilers and one 500KW Viessman Vitoplex100 boiler.

The Chappee Arizona boilers are equipped with a body of double-range heater of fumes. The pipes of the tubular bundle, forming the second course, are located at the top of the heating body avoiding so the formation of condensates. The burner of these boilers has two progressive stages of power and the possibility of operation with power modulation with the control panel of the automatic controller RWF40.

Vitoplex 100 type SX1, with thermal power of $500 \mathrm{~kW}$ is a low temperature gas boiler. This is a threepass boiler for operation with modulating boiler water temperature. The burner of this boiler is a Vitoflame 100 pressure-jet gas burner, equipped with a Boiler control unit for constant boiler water temperature.

The burners of these boilers are of the SICMA type GS151RAG with two power stages of 1000$2000 \mathrm{KW}$, respectively Vitoflame 100 with two power stages between $380-560 \mathrm{KW}$. There were also 22 Grundfoss pumps MG90LA4, two heat exchangers with plates and 2 buffer tanks. 

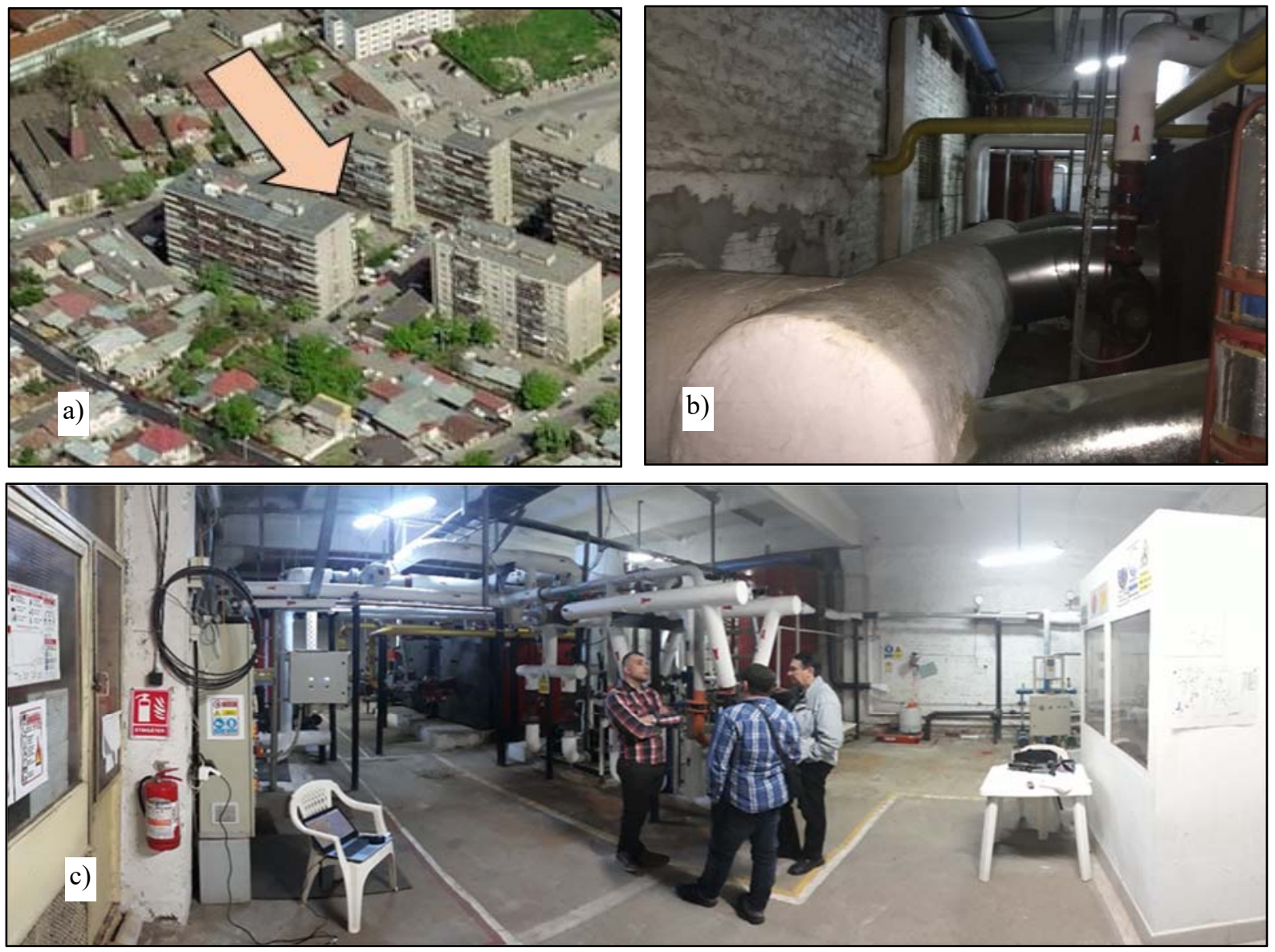

Fig.1 - Thermal plant. a) Boiler plant location b) Photo inside the thermal plant, c) Noise protection solution for the chimney

The boiler chimney (Fig.1b) is made of metallic material, insulated with mineral wool and covered with gypsum. The boilers are placed on puffers and their own foundation. The three burners do not have sound absorption housing, and the pipe connections are made by metal bracelets. The heating installation does not have flexible connections to ducts of the boiler (thermal / gas / fluid). There is no other noise protection like sound attenuator at chimney (in pipe or in quarter-wave) or walls captured with mineral wool or/and plasterboard.

Five types of measurements were made for each thermal power plant:

- dimensions (room, equipment, windows, doors, chimney).

- gas pressure and temperature. $\mathrm{p}_{\mathrm{g}}=0.03[\mathrm{bar}] ; \mathrm{T}_{\mathrm{g}}[\mathrm{oC}]$;

- reverberation time inside the thermal plant (EDT, T20, T30);

- $\quad$ sound pressure level ,Lp [dB], and global weighted sound pressure level, LAeq [dBA] for all audible spectrum octaves $16 \mathrm{~Hz}, 31.5 \mathrm{~Hz}, 63 \mathrm{~Hz}, 125 \mathrm{~Hz}, 250 \mathrm{~Hz}, 500 \mathrm{~Hz}, 1000 \mathrm{~Hz}, 2000 \mathrm{~Hz}$, $4000 \mathrm{~Hz}, 8000 \mathrm{~Hz}$

- gas consumption for each thermal power: two indexes ant time period

The burner stage control was set using the boiler control panel by selecting the desired step, as shown below. A number of 12 operating condition of the boiler are presented in Table 1. The first case is the situation where no equipment is working. Every boiler has a circulating pump, which circulate water within the boiler to enhance boiler operation. To analyze the noise produced by these equipment, the burner of two boilers were switched off, and the pumps functioned either together or separately (cases 2-4). Cases 5-12 are situations in which burner operate simultaneously, at different power stages. 
Operating condition of the boiler

\begin{tabular}{|c|c|c|c|c|}
\hline Case [-] & Pump Boiler 1 [-] & Pump Boiler 2 [-] & Burner 1 [-] & Burner 2 [-] \\
\hline 1 & OFF & OFF & OFF & OFF \\
\hline 2 & ON & ON & OFF & OFF \\
\hline 3 & ON & OFF & OFF & OFF \\
\hline 4 & ON & ON & OFF & OFF \\
\hline 5 & ON & ON & OFF & STAGE 1 \\
\hline 6 & ON & ON & OFF & STAGE 2 \\
\hline 7 & ON & ON & STAGE 1 & OFF \\
\hline 8 & ON & ON & STAGE 1 & STAGE 1 \\
\hline 9 & ON & ON & STAGE 1 & STAGE 2 \\
\hline 10 & ON & ON & STAGE 2 & OFF \\
\hline 11 & ON & ON & STAGE 2 & STAGE 1 \\
\hline 12 & ON & ON & STAGE 2 & STAGE 2 \\
\hline
\end{tabular}

For the fuel consumption measurement, the initial and final index of gas meter was recorded for a period of $1 \mathrm{~min}$. During this time the noise measurements were made inside the technical space. Before the actual measurements began, the gas temperature and pressure were recorded (Fig.2).

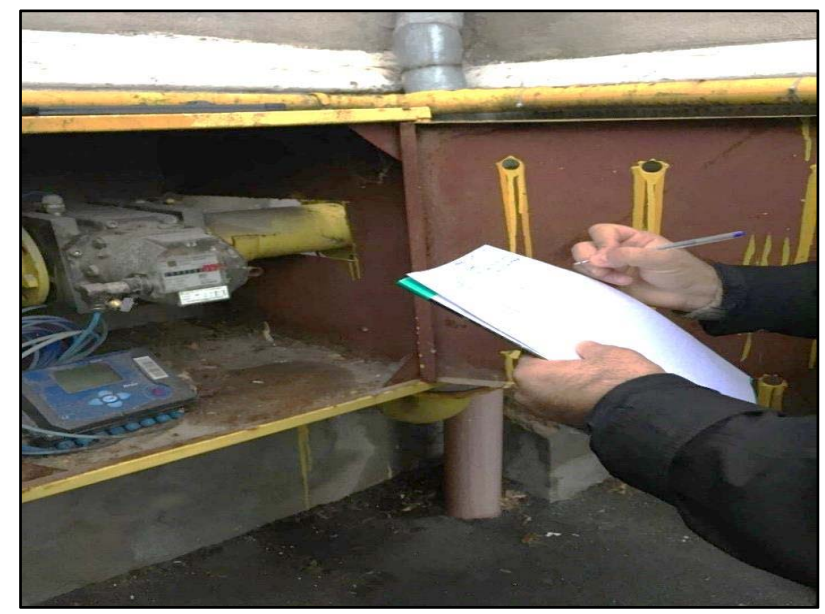

Fig.2 - Reading of gas index and gas parameter

The measurement of the noise level was carried with a 2250 sound meter from Bruel\&Kjaer. The point from which the measurements were made is represented in Fig.3 with blue. This point was situated at the heights that the [9] standard established. The noise measurement was recorded at 1 meter distance from the burner, measured according to the norms. With red dot are the two main noise source of the technical space (the two boilers burners that were on).

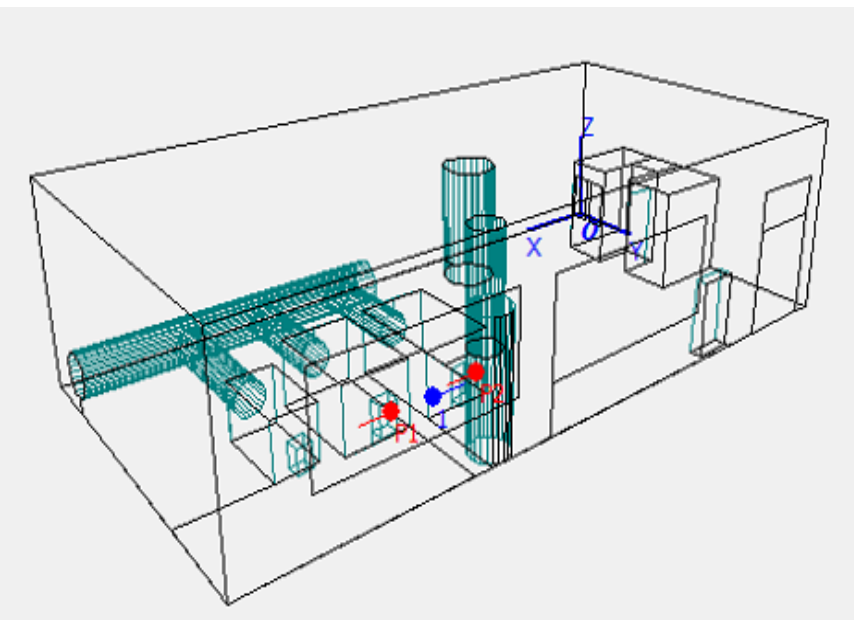

Fig.3 - Burner position (noise sources) and receiver (B\&K Sound meter) 
The reverberation time was also measured using the same sound meter and a noise source, we record the decay curves for all frequency bands and the reverberation time is calculated by means of the sound meter software for all frequencies.

\section{The database and results}

The gas measurements and the real thermal power are presented in Table 2, calculated based on the gas consumption, which is the difference between the final index and the initial reading from the gas meter by one of the participants in the experiment.

Table 2

Gas consumption and parameters

\begin{tabular}{|c|c|c|c|c|}
\hline Case $[-]$ & Initial Index $\left[\mathrm{m}^{3}\right]$ & Final Index $\left[\mathrm{m}^{3}\right]$ & Consumption $\left[\mathrm{m}^{3}\right]$ & $\Phi_{\text {arz }}[\mathrm{kW}]$ \\
\hline 1 & 2525764.38 & 2525764.38 & 0.00 & 0.00 \\
\hline 2 & 2525764.38 & 2525764.38 & 0.00 & 0.00 \\
\hline 3 & 2525764.38 & 2525764.38 & 0.00 & 0.00 \\
\hline 4 & 2525764.38 & 2525764.38 & 0.00 & 0.00 \\
\hline 5 & 2525764.38 & 2525766.33 & 1.95 & 1134.68 \\
\hline 6 & 2525768.80 & 2525770.35 & 1.55 & 901.92 \\
\hline 7 & 2525773.30 & 2525774.80 & 1.50 & 872.83 \\
\hline 8 & 2525781.30 & 2525784.76 & 3.46 & 2013.33 \\
\hline 9 & 2525788.30 & 2525791.72 & 3.42 & 1990.05 \\
\hline 10 & 2525776.20 & 2525777.38 & 1.18 & 686.62 \\
\hline 11 & 2525797.40 & 2525800.85 & 3.45 & 2007.51 \\
\hline 12 & 2525805.20 & 2525808.20 & 3.00 & 1745.66 \\
\hline
\end{tabular}

The following formula was used to determine the actual thermal load of the boiler:

$$
\Phi_{\text {burner }}=\frac{I_{F}-I_{I}}{60} \cdot \frac{p_{g}+p_{0}}{p_{0}} \cdot \frac{T_{0}}{T} \cdot H_{i}
$$

where: $\Phi_{\text {burner }}, \mathrm{kW}$, is real thermal power for 60 seconds;

$I_{F}, \mathrm{~m}^{3}$, and $I_{I}, \mathrm{~m}^{3}$, are the final index and initial read recording from the gas meter;

$H_{\text {I comb }}, \mathrm{kJ} / \mathrm{m}^{3} \mathrm{~N}$, is the low fuel calorific value, $H_{\text {Icomb }}=35371.70\left[\mathrm{~kJ} / \mathrm{m}^{3} \mathrm{~N}\right]$;

$\mathrm{p}_{\mathrm{o}}$, bar, is the atmospheric pressure, $\mathrm{p}_{\mathrm{o}}=1.01325$ [bar]

$\mathrm{T}, \mathrm{K}$, is the gas temperature under normal conditions.

It can be seen from the Fig.4 that the noise level for the situation where no equipment (yellow) works is below $40 \mathrm{~dB}$ for each frequency. When starting pumps (blue, green and brown), the noise level increases up to $57 \mathrm{~dB}$ at the $1000 \mathrm{~Hz}$ frequency. After starting burners the noise level increases above $75 \mathrm{~dB}$ at $1000 \mathrm{~Hz}$ and is directly proportional to the thermal load. For frequencies between 500 and $4000 \mathrm{~Hz}$ this exceeds the norm in more than half of the operating scenarios.

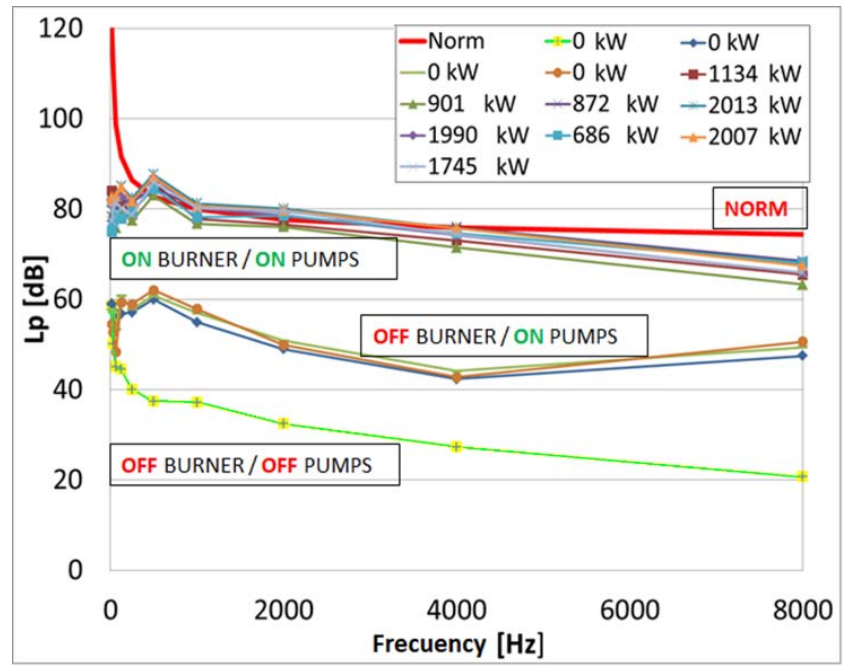

Fig.4 - Comparison between noise level on each frequency and Cz80 from norms 
It is noticed that the noise level has different values depending on the frequencies. Another observation is that for higher frequencies the measurements of noise level have higher values compared to the low frequency noise level. From medium to high frequencies the noise level has a downward trend. There is a difference of up to $15 \mathrm{~dB}$ for the noise level measured at $1000 \mathrm{~Hz}$ compared to the noise level at $8000 \mathrm{~Hz}$.

Another noise level measurements collected was noise level, measured using the filter specified as the A-curve. In the Fig.5 has been compared global noise levels weighted after curve A for all 12 operating situations with the noise value from technical data sheet of boiler and the value imposed by [8].

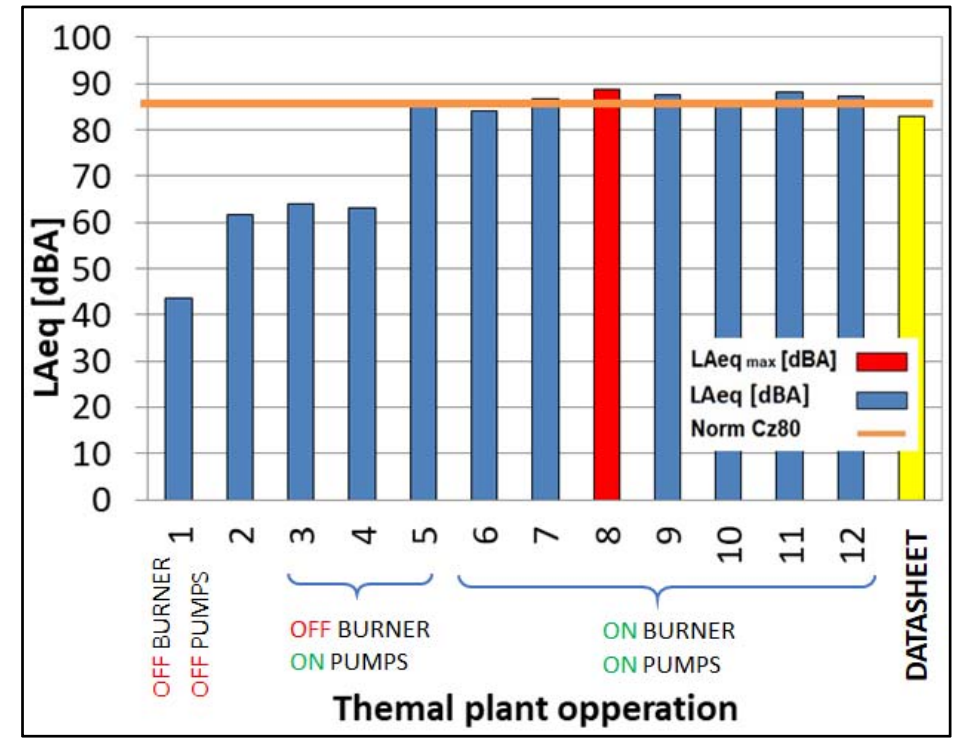

Fig.5 - Comparison between global weight equivalent noise level, boiler data sheet and Cz80 from norms

It is noticed that measurements for all operating conditions of the boilers exceed the values $\square$ indicated from datasheet and is higher than $85 \mathrm{~dB}(\mathrm{~A})$ from norm [8]. The conclusion is that this thermal plant needs an acoustic refurbishment in order to full fill today's acoustic norms.

In the figures below, the dependence between the noise level for each frequency and the thermal load of the burner will be studied. From Fig.6a it is observed that at low frequency the noise level has value between $75 \mathrm{~dB}$ and $83 \mathrm{~dB}$. An increasing tendency is observed in both graphs, thus validating the prediction models [1] and [2], which have as main parameter for predicting noise level the thermal load. The same increasing trend is also noticeable in Fig.6b. For average frequencies, the noise level is between $77 \mathrm{~dB}$ and $87 \mathrm{~dB}$. For $500 \mathrm{~Hz}$ measured noise level the model shows a good fit as the R squared of 0.77 indicates. At high frequencies the noise level is not as well fitted and the measurements value is lower, up to $63 \mathrm{~dB}$ at the frequency of $8000 \mathrm{~Hz}$ (Fig.6c)

The coefficient of determination, R2, is represented in Fig. 6 and this value is used to analyze how differences in one variable can be explained by a difference in a second variable. Subsequently, $\mathrm{R}$ is calculated and corresponds to correlation coefficients, but for nonlinear variation tendencies.

In acoustics, phenomena vary depending on the frequencies studied, so the rules are broken down at each frequency. And in this study we looked at the dependence between Lp and $\Phi_{\text {burner for }}$ different frequencies. 

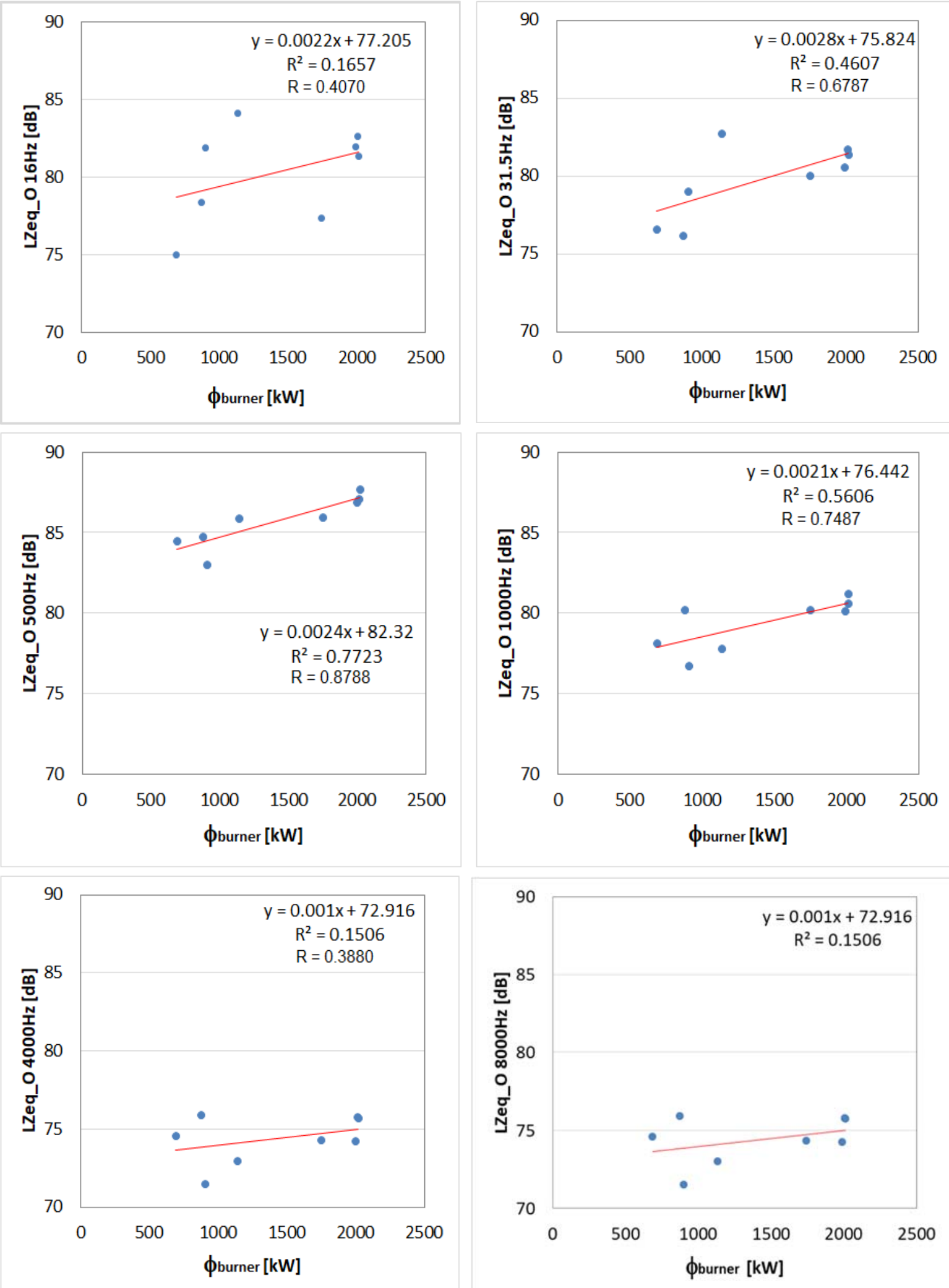

Fig.6 - Recorded sound pressure level based on thermal power for a) low frequencies $(16 \mathrm{~Hz}, 31.5 \mathrm{~Hz})$; b) medium frequencies $(500 \mathrm{~Hz}, 1000 \mathrm{~Hz})$ and c) high frequencies $(4000 \mathrm{~Hz}, 8000 \mathrm{~Hz})$

Fig.7 depicts the relationship between equivalent noise level (LAeq) and thermal power $\square$ burner. From this graph we can see the increasing tendency of the equivalent noise level depending on the thermal load of the boiler. This increase validates the prediction models from the literature, which have their component and thermal load, as the main parameter. 


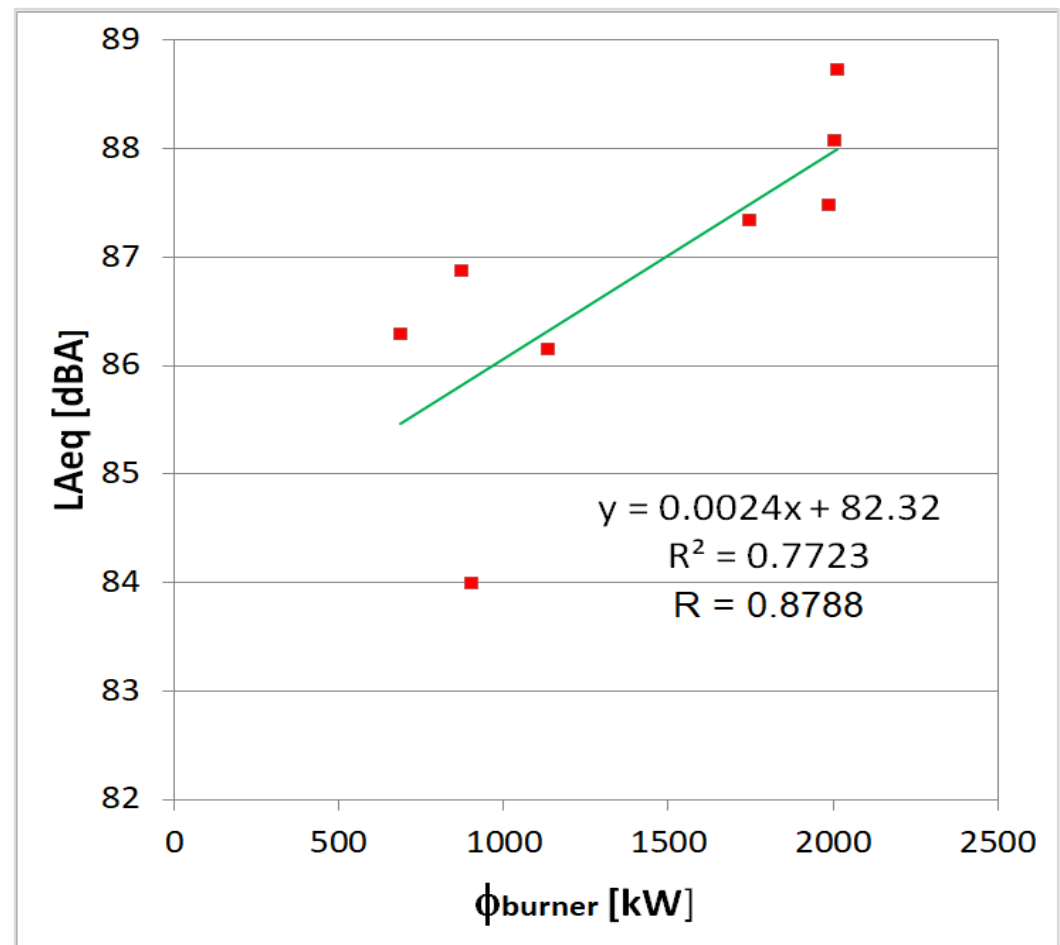

Fig.7 - Equivalent noise level based on actual thermal power, equation and $\mathrm{R}^{2}$

Further, we study the adaptability of predictive models of noise level for the analysed thermal plant. Cyssau's model [1], as well as Hamayon's model [2], predicts the global weighted equivalent noise level. These values were compared with the measurements obtained during the experiment to highlight if the errors of the two models are centered in 0 and if they are adapted for modern thermal power plants and new equipment.

Compared to our measurements, Cyssau's model [1] has an error between $11 \mathrm{dBA}$ (for 2000kW) and $13 \mathrm{dBA}$ (for $700 \mathrm{~kW}$ ), higher than $10 \mathrm{dBA}$ declared by the author (Fig.8). The errors of the Cyssau's model compared to our experimental data are not centred in zero. We conclude that Cyssau's model is not suited for today's thermal powers and for the new thermal generation equipment.

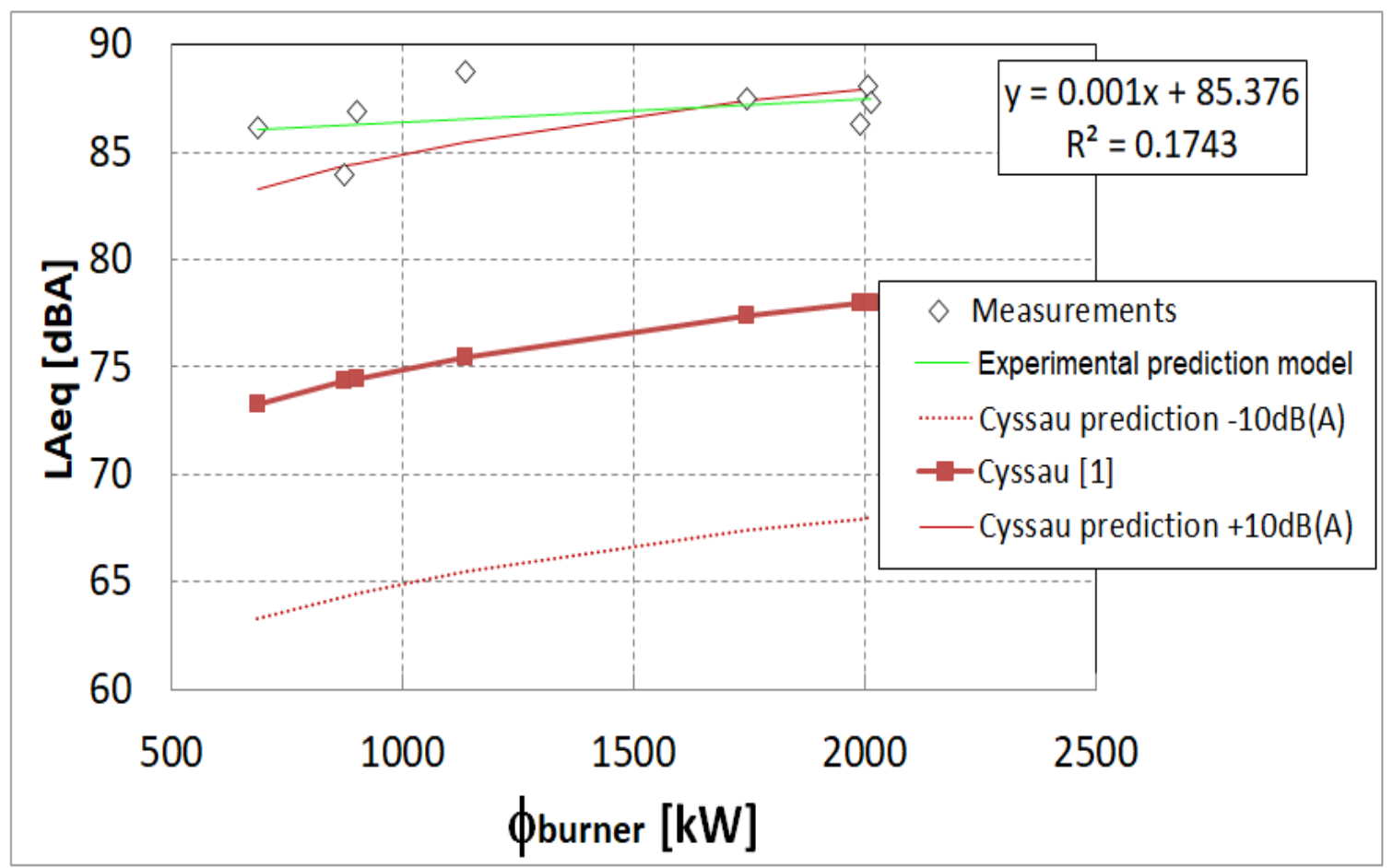

Fig.8 - Comparison between measured and predicted noise level values, Cyssau [1] 
Hamayon's model [2] present slightly higher errors: between $11 \mathrm{dBA}$ (for 2000kW) and $15 \mathrm{dBA}$ (for $700 \mathrm{~kW}$ ), higher than $5 \mathrm{dBA}$ declared by the author. The graph from Fig.9 shows that Hamayon's model predicts lower noise levels than those measured for 8 different thermal powers, and the lower and upper limit of its error is far from the measurements made during the experiment. Similar to Cyssau's model, Hamayon's model present errors that are not centred in zero. In conclusion Hamayon's model is not suited either, for today's thermal powers and for the new thermal generation equipment.

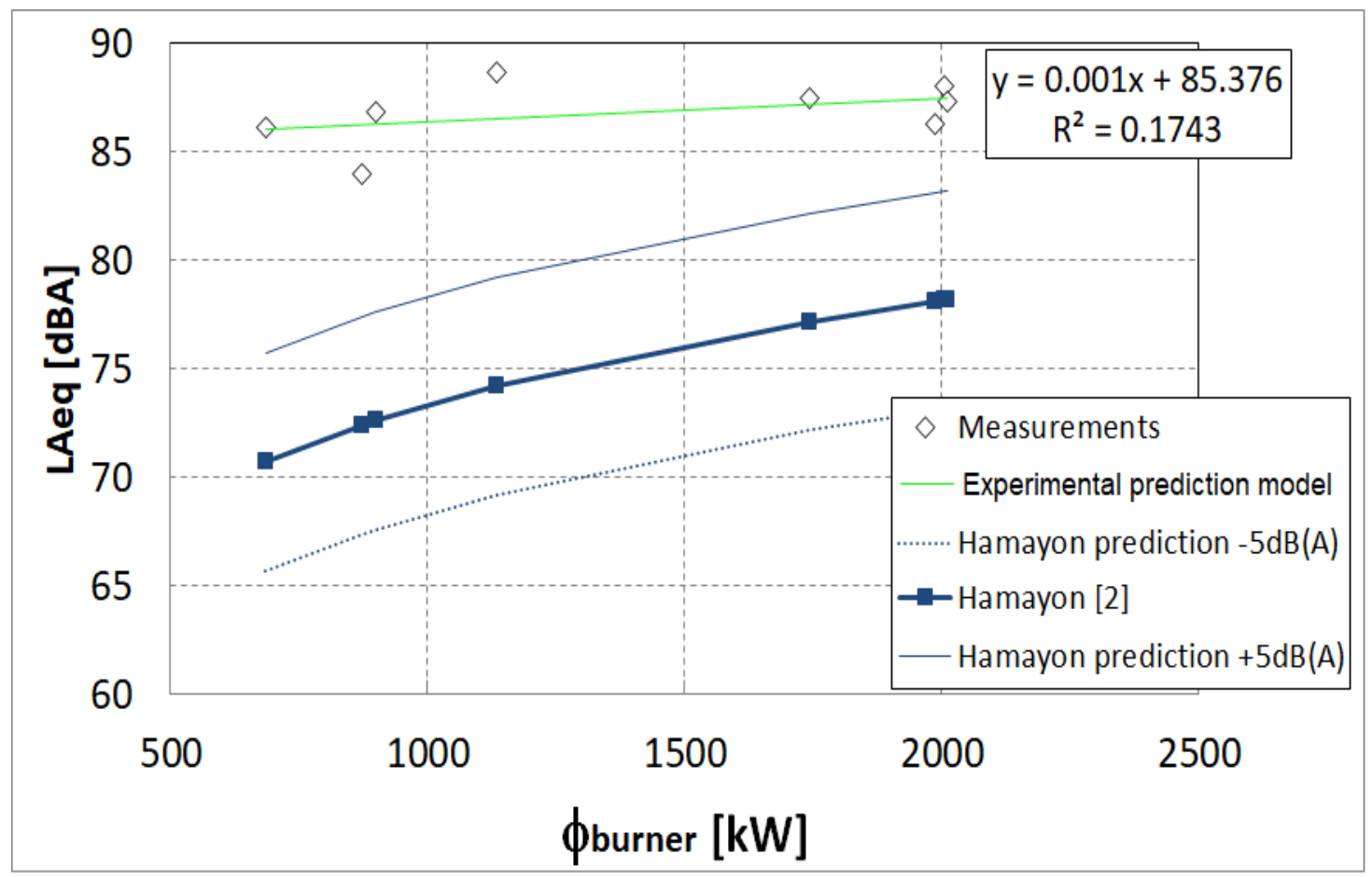

Fig.9 - Comparison between measured and predicted noise level values, Hamayon [2]

Therefore there is need for an adaptation of the noise prediction models to today's thermal conditions (larger thermal power stations, noisier equipment and automation control).

\section{Conclusions}

There is a resonable consensus that the equipment that produces a high noise level in a thermal plant is the burner, and not pumps or other components of the heating system.

From the analyzes made in comparison with the datasheet, there were revealed overtaking of the values given by the producer of the burner, which indicate differences due to faulty equipment settings. Also in this study were highlighted that the measurements of the noise levels exceeding the maximum value indicated in the norm [8]. Out of the 7 operating situations of the burners in 6 were found exceedances of the value of $85 \mathrm{dBA}$. For case 8 , the highest noise level was recorded, with $3 \mathrm{dBA}$ greater than the value imposed by the norm and in the other cases the exceedances of the norm value were between $1.33 \%$ and $4.19 \%$.

The increasing tendency of the equivalent noise level depending on the thermal load of the boiler is another very useful conclusion for designers to estimating the noise level. So when a building requires a higher installed thermal load, designers need to take into consideration the higher noise level generated in the thermal plant room in order to ensure the comfort parameters indoors.

The acuracy of the existing prediction models of the noise level inside the thermal plant room, is higher than the error characterizing the models. Therefore there is need for an adaptation of the noise prediction models to today's thermal conditions (larger thermal power stations, noisier equipment, and automation control). New prediction model should be based on new experimental campaign for the new type of thermal plants and the new installed equipment. 


\section{References}

[1] Cyssau, R., Palenzuela, D. \& Francoise E. (1997). Bruit des equipments. Collection des guides de l'AICVF. France: Ed PYC Edition livres

[2] Hamayon, L. (2001). Reussir l'acoustique d'un batiment. France: Ed. Le Montieur

[3] United States Building Council (2009). LEED ${ }^{\mathrm{TM}}$, Guide of reference, Version: 3.0. USA: Ed. USBC.

[4] American National Standard Acoustical Performance Criteria (2002). Performance Criteria, Design. Requirements, and Guidelines for Schools. ASA S12.60 PART 1. USA

[5] Ocupational Safety and Health Standards (2003). Occupational noise exposure. 29 CFR 1910.25. USA

[6] European Parliament and of the Council (2003). Directive 2003/10/CE on the minimum health and safety requirements regarding the exposure of workers to the risks arising from physical agents. Eurpean Union: Ed. European Parliament and of the Council

[7] International Organization for Standardization (2009). Acoustics- Determination of occupational noise exposureEngineering method. EN ISO 9612:2009, Switzerland

[8] Monitorul oficial al Romaniei (2012). Normativ privind acustica în construcții și zone urbane C125-2013. Romania: Guvernul Romaniei. Ministrul dezvoltării regionale şi turismului. (romanian)

[9] International Organization for Standardization. (2017). Acoustics - Description, measurement and assessment of environmental noise - Part 2: Determination of sound pressure levels. ISO 1996-2:2017. USA

[10] Vianna, K., Cardoso, M. \& Rodrigues, R. (2015). Noise pollution and annoyance: An urban soundscapes study, Noise Health. 17(76): 125-133. doi: 10.4103/1463-1741.155833

[11] Tandel, B.N, \& Jem, M. (2013). Assessment and Mlr Modelling Of Urban Traffic Noises at Major Arterial Roads of Surat. Journal of Environmental Research and Development. 2013; 7(4A):1703-1709.

[12] Méline, J., Van Hulst, A., Thomas, F., Karusisi, N \& Chaix, B. (2013). Transportation noise and annoyance related to road traffic in the French RECORD study. Int J Health Geogr. 2013;12:44.

[13] Brambilla, G., Gallo. V, \& Zambon. G. (2013). The Soundscape quality in some urban parks in Milan, Italy. Int J Environ Res Public Health. 2013;10:2348-6

[14] Iordache, V. \& Catalina, T. (2013). Experimental investigation on the sound pressure level for a high thermal capacity burner during a running cycle. JOURNAL Applied Acoustics, Volume: 74 Issue: 5 Pages: 708-717

[15] Tacutu, L., Pocola, A., Balan, M. \& Iordache, V. (2017). Acoustic measurements for two configurations of acoustic casings with applications on ambient noise pollution, Conference: 8th International Conference on ENERGY and ENVIRONMENT (CIEM). 19-20 October 2017 (pp. 129-133). Bucharest, Romania: International Conference on Energy and Environment. 